\title{
The impact of early administration of vasopressor agents for the resuscitation of severe hemorrhagic shock following blunt trauma
}

Kenichiro Uchida*, Tetsuro Nishimura, Naohiro Hagawa, Shinichiro Kaga, Tomohiro Noda, Naoki Shinyama, Hiromasa Yamamoto and Yasumitsu Mizobata

\begin{abstract}
Background: When resuscitating patients with hemorrhagic shock following trauma, fluid volume restriction and permissive hypotension prior to bleeding control are emphasized along with the good outcome especially for penetrating trauma patients. However, evidence that these concepts apply well to the management of blunt trauma is lacking, and their use in blunt trauma remains controversial. This study aimed to assess the impact of vasopressor use in patients with blunt trauma in severe hemorrhagic shock.
\end{abstract}

Methods: In this single-center retrospective study, we reviewed records of blunt trauma patients with hemorrhagic shock and included patients with a probability of survival $<0.6$. Vital signs on arrival, characteristics, examinations, concomitant injuries and severity, vasopressor use and dose, and volumes of crystalloids and blood infused were compared between survivors and non-survivors. Data are described as median (25-75\% interquartile range) or number.

Results: Forty patients admitted from April 2014 to September 2019 were included. Median Injury Severity Score in survivors vs non-survivors was 41 (36-48) vs $45(34-51)(p=0.48)$, with no significant difference in probability of survival between the two groups (0.22 [0.12-0.48] vs 0.21 [0.08-0.46]; $p=0.93)$. Despite no significant difference in patient characteristics and injury severity, non-survivors were administered vasopressors significantly earlier after admission and at significantly higher doses. Total blood transfusion amount administered within $24 \mathrm{~h}$ after admission was significantly higher in survivors (8430 [5680-9320] vs 6540 [4550-7880] mL; $p=0.03$ ). Max catecholamine index was significantly higher in non-survivors (2 [0-4] vs 14 [10-18]; $p=0.008$ ), and administered vasopressors were terminated significantly earlier (12 [4-26] vs 34 [10-74] hours; $p=0.026$ ) in survivors.

Although the variables of severity of the patients had no significant differences, vasopressor use (Odds ratio [OR] $=$ 21.32, 95\% confident interval [Cl]: 3.71-121.6; $p=0.0001)$ and its early administration (OR=10.56,95\%Cl: 1.90-58.5; $p=$ 0.005 ) indicated significant higher risk of death in this study.

(Continued on next page)

\footnotetext{
* Correspondence: cvs.uchida@gmail.com

Department of Traumatology and Critical Care Medicine, Osaka City University, Graduate school of medicine, , 1-5-7, Asahi-machi, Abeno-ku, Osaka City, Osaka 545-8585, Japan
}

C C The Author(s). 2020 Open Access This article is licensed under a Creative Commons Attribution 4.0 International License, which permits use, sharing, adaptation, distribution and reproduction in any medium or format, as long as you give appropriate credit to the original author(s) and the source, provide a link to the Creative Commons licence, and indicate if changes were made. The images or other third party material in this article are included in the article's Creative Commons licence, unless indicated otherwise in a credit line to the material. If material is not included in the article's Creative Commons licence and your intended use is not permitted by statutory regulation or exceeds the permitted use, you will need to obtain permission directly from the copyright holder. To view a copy of this licence, visit http://creativecommons.org/licenses/by/4.0/ The Creative Commons Public Domain Dedication waiver (http://creativecommons.org/publicdomain/zero/1.0/) applies to the data made available in this article, unless otherwise stated in a credit line to the data. 
(Continued from previous page)

Conclusion: Vasopressor administration and high-dose use for resuscitation of hemorrhagic shock following severe blunt trauma are potentially associated with increased mortality. Although the transfused volume of blood products tends to be increased when resuscitating these patients, early termination of vasopressor had better to be considered.

Keywords: Resuscitation, Vasopressor, Hemorrhagic shock, Blunt trauma, Multiple trauma

\section{Background}

In the resuscitation of hemorrhagic shock, the priority in its management is the absolute and immediate control of sites of bleeding along with simultaneous volume resuscitation to maintain adequate tissue perfusion [1]. Historically, the importance of permissive hypotension and the restriction of crystalloid fluid volume before hemorrhage control has been emphasized with good outcomes in patients with penetrating trauma $[2,3]$, but recently, several studies have indicated uncertainness of the use of permissive hypotension in trauma patients [4-6]. Furthermore, there is still no evidence of these concepts being successfully applied to the management of patients following blunt injury or those with traumatic brain injury (TBI) [7-9].

Despite these controversies, vasopressors are still globally administered in some trauma patients in severe shock to maintain minimal perfusion pressure especially for the brain or are sometimes used as fluid-sparing adjuncts to resuscitation without diluting clotting factors $[10,11]$. Although many reports do not recommend the use of vasopressors for the resuscitation of trauma patients [12, 13], some reports and guidelines have committed to the temporary use of vasopressors for life-threatening hemorrhagic shock to minimize fluid volume administered and maintain appropriate systemic perfusion [14, 15]. Even in level 1 trauma centers, where any surgical or interventional radiographic procedures for the immediate control of bleeding and early activation of massive transfusion protocol (MTP) are always available, the effects and risks of vasopressor administration for severe hemorrhagic shock following trauma remain unclear [16-19].

Thus, the objective of this study was to evaluate the impact of vasopressor use in patients with blunt traumatic injury who are in severe hemorrhagic shock.

\section{Methods}

\section{Patient selection}

This was a single-center retrospective review of patients admitted to the Trauma and Critical Care Center of Osaka City University Hospital, a level 1 urban area trauma center in the second largest city by population in Japan. We reviewed all patients admitted with trauma during April 2014 and September 2019 who were over 16 years old and included those patients with hemorrhagic shock following blunt trauma injury to the torso and required immediate intervention such as surgery or trans-arterial embolization.
In the current study, hemorrhagic shock was defined as systolic blood pressure less than $100 \mathrm{mmHg}$ on arrival or a ratio of heart rate over systolic blood pressure of $>1$ and an increased lactate level of $>2.5 \mathrm{mmol} / \mathrm{L}$.

We hypothesized that patients with mild to moderate injury simply tend not to be administered vasopressor agents and if administrated, the outcomes of these patients would not be affected by the use of these agents. Under this hypothesis, to evaluate exact impacts of vasopressor administration in severe trauma patients, we excluded the patients with a probability of survival (Ps) score calculated by the Trauma and Injury Severity Score (TRISS) $[20,21]$ of $\geq 0.6$. To evaluate the outcomes and complications of vasopressor administration for the patients, we also excluded patients in cardiopulmonary arrest on arrival, those dying for a brief instant of time within $24 \mathrm{~h}$ after arrival, and patients transferred from other hospitals. The patients were divided into survivors who conclusively discharged to home or transferred for rehabilitation or non-survivors who died during admission.

\section{Data collection}

The factors which supposed to influence the outcomes were investigated from the clinical records. Patient's demographics such as sex, age, past medical history, mechanism of injury, injury severity score and physiological data on arrival were compared.

We also compare the examination results like the results of focused assessment with sonography for trauma (FAST), blood gas data on admission, concomitant injuries, clinical time flow and procedures, total amount of blood transfusion, external cellular fluid in addition to the vasopressor administration and it's timing. These data were all recorded without deficit in our institutional registry.

\section{Resuscitative strategy for trauma and Administration of Vasopressor Agents}

Our resuscitation strategy for trauma patients in shock is based on the Advanced Trauma Life Support guidelines and basically emphasizing the importance of early administration of blood transfusion. When a trauma patient arrives at the hospital, we initially start fluid resuscitation with extracellular fluid infusion. If the patient has sites of bleeding, we assessed the response of hemodynamics to extracellular fluid resuscitation of $<$ 
$1000 \mathrm{~mL}$. Then, if the hemodynamic condition of the patient is still unstable, we immediately administer a transfusion of blood. Although we stock 20 units of red blood cells and 20 units of fresh frozen plasma in the resuscitation room, MTP including cryoprecipitate is always available. Our MTP is based on the current 1:1:1 ratio theory of usage of platelets:fresh frozen plasma:red blood cells, and packs are constantly brought to the resuscitation room with that ratio of composition.

As the highest priority for hemorrhage is control of the sites of bleeding, if the patient is not stable enough to transfer to the operating room, we perform abbreviated interventions such as emergent resuscitative thoracotomy, laparotomy, or retroperitoneal packing in the resuscitation room if needed.

The indications for the administration and timing of vasopressor agents in the resuscitation are completely up to the preference of the trauma surgeon or physician leading the resuscitation. When vasopressors are used in conjunction with volume resuscitation, we usually administer norepinephrine first, especially for hemorrhagic shock, but if a low cardiac ejection fraction is quickly estimated from wall motion in the initial FAST, dopamine is used first in some patients. We defined the early administration of vasopressor as either dopamine or noradrenaline started within $1 \mathrm{~h}$ after admission.

\section{Statistical analysis}

All statistical data are presented as the median $(25-75 \%$ interquartile range [IQR]) or number. Univariate comparisons between the survivor and non-survivor were performed for the factors of demographic, blood examinations, injury severities, and clinical courses. Categorical variables were analyzed with Fischer's exact test. Non-parametric numerical data (presented as median with IQR) were compared using the MannWhitney $U$-test.

Multiple logistic regression analysis was performed for identifying factors affecting survival. The factors significantly different between the two groups in the univariate comparison were used for the independent variables to identify the affecting factors for survival in the multiple logistic regression analysis. A value of $p<0.05$ was considered statistically significant. Data were analyzed using IBM SPSS Statistics, version 22 (SPSS Inc., Chicago, IL).

\section{Results}

In total, 318 patients were admitted during the study period with hemorrhage following traumatic torso injury and required immediate intervention to control bleeding. Ninety-two patients were excluded because of cardiopulmonary arrest on arrival or death within $24 \mathrm{~h}$ after arrival, as were 52 patients with penetrating injury. As six patients were transferred from the other hospitals and
128 patients were of more than 0.6 of Ps, these patients were also excluded.

Finally, 40 patients with blunt trauma and a Ps $<0.6$ were included, and their clinical results were compared in this study (Fig. 1).

The epidemiologic characteristics and initial clinical presentation of the patients in the survivor and nonsurvivor groups are shown in Table 1 . The median age of the survivors vs non-survivors was 58 (42-68) vs 62 (4573 ) years old $(p=0.09)$, and almost $60 \%$ of patients were males in both groups. There were no significant differences between the two groups in the mechanism of injury. The Injury Severity Score (ISS) was 41 (36-48) vs 45 (3451) $(p=0.48)$, respectively. There were no significant differences in physiological signs such as Glasgow Coma Scale, heart rate, respiratory rate, body temperature and systolic blood pressure between the two groups. The Ps score between the two groups also was not significantly different $(0.22[0.12-0.48]$ vs $0.21[0.08-0.46] ; p=0.93)$.

Table 2 shows the results of examinations on admission. There were no significant differences between the two groups with regard to the results of extended FAST, base excess, $\mathrm{pH}$ and lactate level. None of the coagulation-related factors showed a significant difference between the survivors and non-survivors. The injury descriptions classified according to location are shown in Table 3 and we found no significant differences between the two groups.

The clinical courses of the patients are shown in Table 4. MTP was activated in all patients and 6 of 21 $(28.6 \%)$ vs 8 of $19(42.1 \%)$ patients $(p=0.51)$ underwent aortic cross- clamping including resuscitative endovascular balloon occlusion of the aorta (REBOA) in each group. Aortic clamping was performed at a significantly higher rate in the non-survivors. The median time from presentation to the hospital to start surgical procedures for stop the bleeding was $32(15-43)$ vs $38(18-48)$ minutes $(p=0.67)$ and that of interventional radiology was $62(54-76)$ vs $67(59-78)$ minutes $(p=0.79)$. There were no significant differences in the volume of external cellular fluid infused in the resuscitation room before the administration of blood transfusion (750 [400-900] vs 800 [450$960] \mathrm{mL}(p=0.48)$. The total amount of blood transfused within $24 \mathrm{~h}$ after admission was significantly higher in the survivors (8430 [5680-9320] vs 6540 [4550-7880] mL; $p=0.03$ ). Vasopressors were also administered significantly earlier and at higher doses in the non-survivors compared with the survivors. The patients who were administered a vasopressor within one hour after admission had significantly high mortality. The score of the max catecholamine index calculated as [noradrenaline *100+ dopamine $\gamma]$ was significantly higher in the non-survivors (2 [0-4] vs 14 [10-18]; $p=0.008$ ). The administered vasopressors were terminated significantly earlier in the 
Table 1 Demographic data of the patients

\begin{tabular}{|c|c|c|c|}
\hline & $\begin{array}{l}\text { Survivors } \\
N=21\end{array}$ & $\begin{array}{l}\text { Non-survivors } \\
N=19\end{array}$ & $\begin{array}{l}p \\
\text { value }\end{array}$ \\
\hline Sex, male/female & $\begin{array}{l}\text { 12/9 (Male } \\
57.1 \% \text { ) }\end{array}$ & $\begin{array}{l}\text { 10/ } 9 \text { (Male } \\
52.6 \% \text { ) }\end{array}$ & 1.00 \\
\hline Age, years & $58(42-68)$ & $62(45-73)$ & 0.09 \\
\hline ISS & $41(36-48)$ & $45(34-51)$ & 0.48 \\
\hline Mechanism of injury & & & 0.53 \\
\hline Motor vehicle accident & $9(42.9 \%)$ & $11(57.9 \%)$ & \\
\hline Fall from height & $12(57.1 \%)$ & $8(42.1 \%)$ & \\
\hline \multicolumn{4}{|l|}{ Physiological data on arrival } \\
\hline GCS & $8(4-13)$ & $6(3-12)$ & 0.17 \\
\hline RR (breaths per min) & $28(24-30)$ & $30(20-33)$ & 0.88 \\
\hline HR (beats per min) & $120(112-124)$ & $112(98-120)$ & 0.07 \\
\hline $\begin{array}{l}\text { Systolic blood pressure } \\
(\mathrm{mmHg})\end{array}$ & $90(64-104)$ & $76(40-95)$ & 0.25 \\
\hline Body temperature $\left({ }^{\circ} \mathrm{C}\right)$ & $36.1(35.7-36.5)$ & $35.8(34.9-36.2)$ & 0.11 \\
\hline \multicolumn{4}{|l|}{ Past medical history } \\
\hline Stroke & $2(9.5 \%)$ & $1(5.3 \%)$ & 1.0 \\
\hline Cardiac failure & $3(14.3 \%)$ & $1(5.3 \%)$ & 0.6 \\
\hline Respiratory disease & $3(14.3 \%)$ & $2(10.5 \%)$ & 1.0 \\
\hline Chronic kidney disease & $2(9.5 \%)$ & 0 & 0.49 \\
\hline Probability of survival & $0.22(0.12-0.48)$ & $0.21(0.08-0.46)$ & 0.93 \\
\hline
\end{tabular}

ISS injury severity score, GCS Glasgow coma scale, $R R$ respiratory rate, $H R$ heart rate

Statistical data are presented as median (25-75\% IQR) or number survivors compared with the non-survivors (12 [4-26] vs 34 [10-74] hours; $p=0.026$ ).

Although the variables of aortic clamp seemed no significant risk factors for mortality, vasopressor use (Odds ratio $[\mathrm{OR}]=21.32$, 95\% confident interval $[\mathrm{CI}]$ : 3.71121.6; $p=0.0001)$ and its early administration ( $\mathrm{OR}=$ 10.56, 95\%CI: $1.90-58.5 ; p=0.005)$ indicated significant higher risk of death in this study (Table 5).

\section{Discussion}

The advantages and disadvantage of vasopressor administration or continuous volume resuscitation to improve the outcomes for these compromised patients with shock following blunt trauma are still unclear [12, 15, 22-25]. Thus, in this single-center retrospective observational study, we assessed the effects of vasopressor administration especially for the resuscitation of patients with severe blunt trauma. To evaluate the exact outcomes of vasopressor use, we included patients with backgrounds and injury severity that were not significantly different. Under these considerations, the present study found that high-dose use and early administration of vasopressors for the resuscitation of patients with severe blunt trauma had some potential relation to higher mortality. Although significantly more blood products were transfused in the surviving patients, this result potentially emphasizes the importance of the early administration of blood products and the provision of a continuous blood supply based on the 1:1:1 theory before administering high-dose vasopressors.

Globally, the recommendation of vasopressor administration is still quite uncertain. The European trauma

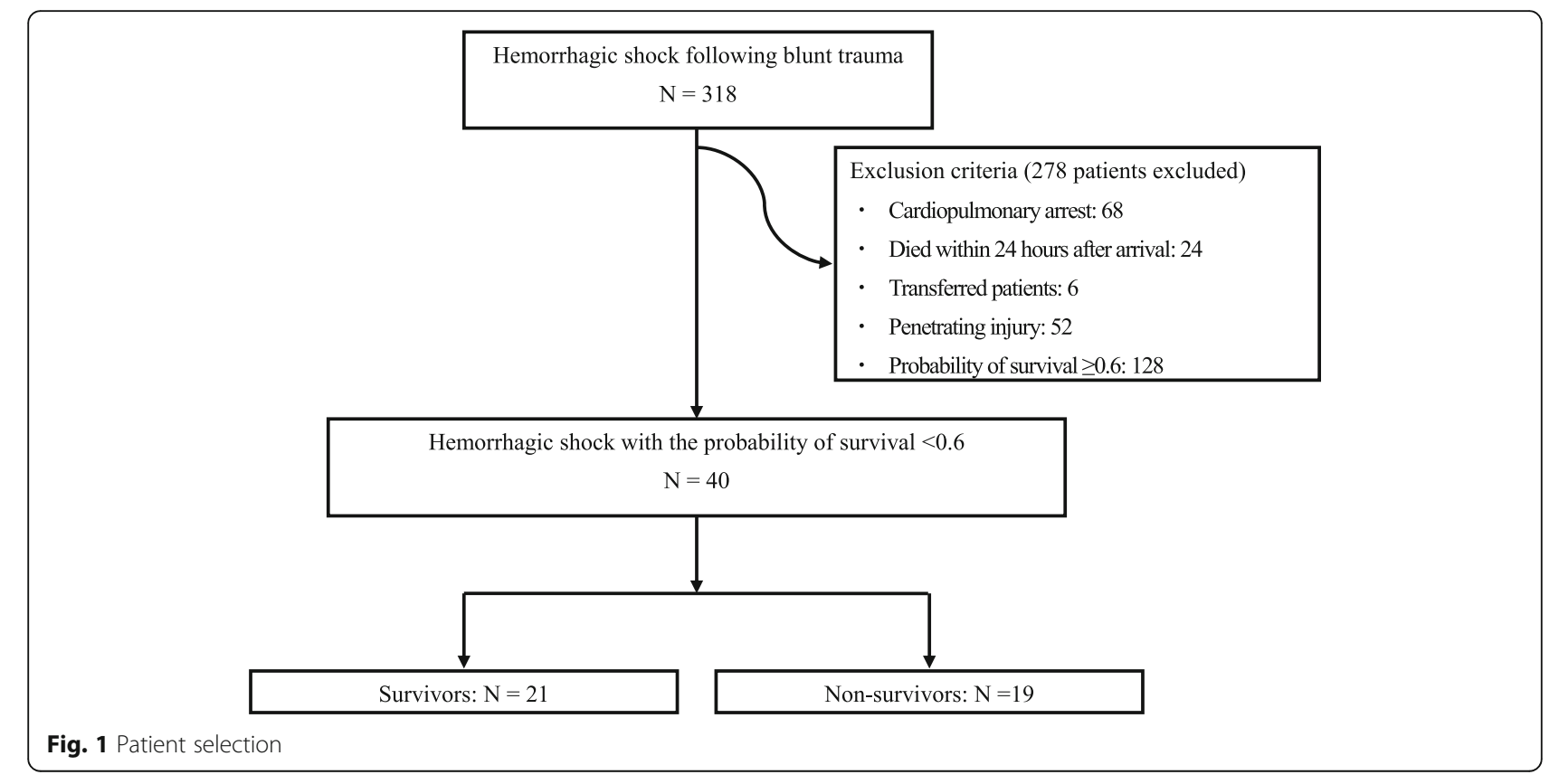


Table 2 Examination results

\begin{tabular}{llll}
\hline & $\begin{array}{l}\text { Survivors } \\
\mathrm{N}=21\end{array}$ & $\begin{array}{l}\text { Non-survivors } \\
\mathrm{N}=19\end{array}$ & $p$ value \\
\hline Positive extended FAST & $14(66.7 \%)$ & $10(52.6 \%)$ & 0.52 \\
Base excess & $-8.6(-12.1--4.8)$ & $-9.6(-13.2--5.1)$ & 0.42 \\
$\mathrm{pH}$ & $7.24(7.15-7.37)$ & $7.20(7.13-7.7 .31)$ & 0.53 \\
Lactate level (mmol/L) & $6.8(3.8-7.8)$ & $8.8(4.7-10.4)$ & 0.15 \\
Fibrinogen level (mg/dL) & $170(169-236)$ & $167(144-255)$ & 0.38 \\
PT-INR & $1.12(1.01-1.15)$ & $1.22(1.05-1.28)$ & 0.36
\end{tabular}

FAST focused assessment with sonography for trauma, PT-INR prothrombin time-international normalized ratio

Statistical data are presented as median (25-75\% IQR)

care providers concluded that although vasopressors are frequently used, their level of recommendation is still controversial [26]. Even more, there are no reports of outcomes of long-term neurological function or quality of life so far.

For the resuscitation of patients with severe hemorrhagic shock following trauma, the first priority is the immediate control of bleeding [3]. However, how appropriate systemic perfusion especially for the cerebral circulation can be maintained or improved is also very important. Currently, although permissive hypotension especially for penetrating trauma is recommended [6, 14], the impact of permissive hypotension could be less beneficial or even cause harm in patients with blunt trauma at high risk for concomitant TBI [6-8]. Although we generally try to minimize the use of fluid resuscitation to avoid dilutional coagulopathy, there are certainly patients in whom we have difficulty in maintaining their blood pressure while performing bleeding control procedures. As is already known historically, excessive administration of external cellular fluids for resuscitation is completely disadvantageous and causes dilutional coagulopathy $[2,27,28]$. Thus, we limit the administered volume to $<1000 \mathrm{~mL}$ in hemorrhagic shock patients following trauma.

Although REBOA is now also one option available for the control of severe infra-diaphragm hemorrhage in trauma patients [29-31], as assessed globally, some outcomes are described in which patients undergoing

Table 3 Injuries occurring in the patients

\begin{tabular}{llll}
\hline & $\begin{array}{l}\text { Survivors } \\
N=21\end{array}$ & $\begin{array}{l}\text { Non-survivors } \\
N=19\end{array}$ & $p$ value \\
\hline Injury & & & \\
Cranial injury (GCS $>8)$ & $8(38.1 \%)$ & $7(36.8 \%)$ & 1.00 \\
Craniofacial injury & $4(19.0 \%)$ & $3(16.8 \%)$ & 1.00 \\
Thoracic injury & $16(76.2 \%)$ & $14(73.7 \%)$ & 1.00 \\
Abdominal injury & $14(66.7 \%)$ & $9(47.4 \%)$ & 0.34 \\
Pelvic injury & $8(38.1 \%)$ & $11(57.9 \%)$ & 0.34 \\
Bony spinal injury & $5(23.8 \%)$ & $8(42.1 \%)$ & 0.31 \\
\hline
\end{tabular}

GCS Glasgow coma scale

Statistical data are presented as median (25-75\% IQR) or number
Table 4 Clinical courses

\begin{tabular}{llll}
\hline & $\begin{array}{l}\text { Survivors } \\
N=21\end{array}$ & $\begin{array}{l}\text { Non-survivors } \\
N=19\end{array}$ & $\begin{array}{l}p \\
\text { value }\end{array}$ \\
\hline Activation of MTP & $21(100 \%)$ & $19(100 \%)$ & 1.00 \\
$\begin{array}{l}\text { Aortic cross-clamping } \\
\text { including REBOA }\end{array}$ & $6(28.6 \%)$ & $8(42.1 \%)$ & 0.51 \\
$\begin{array}{l}\text { Infused volume of ECF (mL) } \\
\text { Time to intervention (min) }\end{array}$ & $750(400-900)$ & $800(450-960)$ & 0.48 \\
$\quad$ Surgery & $32(15-43)$ & $38(18-48)$ & 0.67 \\
$\quad$ Interventional radiology & $62(54-76)$ & $67(59-78)$ & 0.79 \\
$\begin{array}{l}\text { Total amount of blood } \\
\text { transfusion (mL) }\end{array}$ & $8430(5680-$ & $6540(4550-$ & 0.03 \\
$\begin{array}{l}\text { Vasopressor use } \\
\text { Max catecholamine index }\end{array}$ & $9320)$ & $7880)$ & \\
$\begin{array}{l}\text { Vasopressor use }<1 \mathrm{~h} \\
\text { after admission }\end{array}$ & $2(28.6 \%)$ & $17(89.5 \%)$ & 0.0001 \\
$\begin{array}{l}\text { Time to vasopressor } \\
\text { termination (h) }\end{array}$ & $12(4-26)$ & $34(10-18)$ & 0.008 \\
\hline
\end{tabular}

MTP massive transfusion protocol, REBOA resuscitative endovascular balloon occlusion of the aorta, ECF external cellular fluid

Catecholamine index $=$ [noradrenaline $* 100+$ dopamine $]$

Statistical data are presented as median (25-75\% IQR) or number

REBOA placement had significantly more severe complications and higher mortality compared with patients not undergoing REBOA [32, 33]. Although the number of patients who had placed REBOA was too small to evaluate, REBOA placement had seemed no significant differences from the view point of resuscitation in our current study.

As this is the single-center retrospective study, the data have no institutional bias or differences of resuscitative strategies for shock trauma patients. But for the stronger evidence, prospective randomized surveys with larger numbers of patients are needed to evaluate the impact of vasopressor use in the early resuscitation phase and assess long-term outcomes of the patients with severe trauma.

\section{Limitations}

The present study is a small, preliminary report from a single center, and the number of patients is too small to establish definitive conclusions. Thus, we need to plan further multi-institutional, prospective, randomized trials on the basis of this study to better assess the benefits and disadvantages of the administration of vasopressors

Table 5 Risk factors for mortality of hemorrhagic shock following blunt trauma

\begin{tabular}{lll}
\hline & Odds ratio (95\% Cl) & $p$ value \\
\hline Activation of MTP & $1.11(0.021-58.49)$ & 1.00 \\
Aortic clamp including REBOA & $0.55(0.15-2.05)$ & 0.51 \\
Vasopressor use & $21.32(3.71-121.6)$ & 0.0001 \\
Vasopressor use < 1 h after admission & $10.56(1.90-58.5)$ & 0.005 \\
\hline
\end{tabular}

Cl confidence interval, MTP massive transfusion protocol, REBOA resuscitative endovascular balloon occlusion of the aorta 
for severe hemorrhagic shock in patients following blunt trauma.

\section{Conclusion}

The present findings highlight that the administration of vasopressors and high-dose use in the resuscitation of hemorrhagic shock following severe blunt trauma are potentially associated with increased mortality. In the resuscitation of these patients, even if the transfused volume of blood products tends to be increased, the early termination of vasopressor therapy had better to be considered.

\section{Abbreviations}

TBI: Traumatic brain injury; MTP: Massive transfusion protocol; Ps: Probability of survival; TRISS: Trauma and injury severity score; FAST: Focused assessment with sonography for trauma; IQR: Interquartile range; ISS: Injury severity score; REBOA: Resuscitative endovascular balloon occlusion of the aorta; OR: Odds ratio; $\mathrm{Cl}$ : Confident interval.

\section{Acknowledgements}

Nothing.

We herein declare that all authors have no conflicts of interest with regards to this study.

We also have not received any funding with regards to this study and manuscript.

\section{Authors' contributions}

$\mathrm{KU}$ organized and coordinated the study design and wrote the initial draft of this manuscript. KU, NH, SK, NS, TN2 extracted data. TN1 contributed to data cleaning and advised statistical analysis of the data. TN1, HY and YM reviewed and modified the manuscript. All authors read and approved the final manuscript.

\section{Funding}

All the authors report no sources of funding.

\section{Availability of data and materials}

The data generated and analyzed during this study are available from the authors on reasonable request.

\section{Ethics approval and consent to participate}

As this was a retrospective study, the written informed consent was not able to be obtained from the patients. Under considering these conditions, the institutional ethical review board of Osaka City University waived the need for informed consent and approved for this study [Approval number: 4387]

\section{Consent for publication}

Not applicable for this study.

\section{Competing interests}

The authors declare that they have no competing interests.

Received: 30 October 2019 Accepted: 8 April 2020

Published online: 16 April 2020

References

1. Teixeira PG, Inaba K, Hadjizacharia P, Brown C, Salim A, Rhee P, Browder T, Noguchi TT, Demetriades D. Preventable or potentially preventable mortality at a mature trauma center. J Trauma. 2007;63(6):1338-47.

2. David JS, Voiglio EJ, Cesareo E, Vassal O, Decullier E, Gueugniaud PY, Peyrefitte S, Tazarourte K. Prehospital parameters can help to predict coagulopathy and massive transfusion in trauma patients. Vox Sang. 2017; 112:557-66.

3. American College of Surgeons Committee on Trauma. ATLS Advanced Trauma Life Support for Doctors. Student Course Manual: Ninth Edition. Chicago: American College of Surgeons, Committee on Trauma; 2012.
4. Kwan I, Bunn F, Chinnock P, Roberts I. Timing and volume of fluid administration for patients with bleeding. Cochrane Database Syst Rev. 2014;3:CD002245

5. Wang $\mathrm{CH}$, Hsieh WH, Chou HC, Huang YS, Shen JH, Yeo YH, Chang HE, Chen SC, Lee CC. Liberal versus restricted fluid resuscitation strategies in trauma patients: a systematic review and meta-analysis of randomized controlled trials and observational studies*. Crit Care Med. 2014;42(4):95461.

6. Bickell WH, Wall MJ Jr, Pepe PE, Martin RR, Ginger VF, Allen MK, Mattox KL. Immediate versus delayed fluid resuscitation for hypotensive patients with penetrating torso injuries. N Engl J Med. 1994;331(17):1105-9.

7. Morrison CA, Carrick MM, Norman MA, Scott BG, Welsh FJ, Tsai P, Liscum KR Wall MJ Jr, Mattox KL. Hypotensive resuscitation strategy reduces transfusion requirements and severe postoperative coagulopathy in trauma patients with hemorrhagic shock: preliminary results of a randomized controlled trial. J Trauma. 2011;70(3):652-63.

8. Chesnut RM, Marshall LF, Klauber MR, Blunt BA, Baldwin N, Eisenberg HM, Jane JA, Marmarou A, Foulkes MA. The role of secondary brain injury in determining outcome from severe head injury. J Trauma. 1993;34(2):216-22.

9. Rossaint R, Bouillon B, Cerny V, Coats TJ, Duranteau J, Fernández-Mondéjar E, Filipescu D, Hunt BJ, Komadina R, Nardi G, et al. The European guideline on management of major bleeding and coagulopathy following trauma: fourth edition. Crit Care. 2016:20:100.

10. McHugh GS, Engel DC, Butcher I, Steyerberg EW, Lu J, Mushkudiani N, Hernández AV, Marmarou A, Maas Al, Murray GD. Prognostic value of secondary insults in traumatic brain injury: results from the IMPACT study. J Neurotrauma. 2007;24(2):287-93.

11. Dutton RP, Mackenzie CF, Scalea TM. Hypotensive resuscitation during active hemorrhage: impact on in-hospital mortality. J Trauma. 2002;52(6):1141-6.

12. Sperry JL, Minei JP, Frankel HL, West MA, Harbrecht BG, Moore EE, Maier RV, Nirula R. Early use of vasopressors after injury: caution before constriction. J Trauma. 2008:64(1):9-14.

13. Plurad DS, Talving P, Lam L, Inaba K, Green D, Demetriades D. Early vasopressor use in critical injury is associated with mortality independent from volume status. J Trauma. 2011;71(3):562-5.

14. Spahn DR, Bouillon B, Cerny V, Coats TJ, Duranteau J, Fernández-Mondéjar E, Filipescu D, Hunt BJ, Komadina R, Nardi G, et al. Management of bleeding and coagulopathy following major trauma: an updated European guideline. Crit Care. 2013;17(2):R76

15. Fangio P, Asehnoune K, Edouard A, Smail N, Benhamou D. Early embolization and vasopressor administration for management of lifethreatening hemorrhage from pelvic fracture. J Trauma. 2005;58(5):978-84

16. Hylands M, Toma A, Beaudoin N, Frenette AJ, D'Aragon F, Belley-Côté É, Charbonney E, Møller MH, Laake JH, Vandvik PO, et al. Early vasopressor use following traumatic injury: a systematic review. 2017;7(11):e017559.

17. Cohn SM, McCarthy J, Stewart RM, Jonas RB, Dent DL, Michalek JE. Impact of low-dose vasopressin on trauma outcome: prospective randomized study. World J Surg. 2011;35(2):430-9

18. Sims CA. AVERT shock: Arginine vasopressin during the early resuscitation of traumatic shock. 2012. Available at: https://clinicaltrials.gov/show/NCT01611 935. Accessed May 5th, 2019.

19. Lienhart HG, Wenzel V, Braun J, Dörges V, Dünser M, Gries A, Hasibeder WR, Helm M, Lefering $R$, Schlechtriemen $T$, et al. Vasopressin for therapy of persistent traumatic hemorrhagic shock: the VITRIS. Study. Anaesthesist. 2007;56:145-8 150. In German.

20. Champion HR, Sacco WJ, Copes WS, Gann DS, Gennarelli TA, Flanagan ME. A revision of the trauma score. J Trauma. 1989;29:623-9.

21. Boyd CR, Tolson MA, Copes WS. Evaluating trauma care: the TRISS method. Trauma score and the injury se- verity score. J Trauma. 1987;27:370-8.

22. Beloncle F, Meziani F, Lerolle N, Radermacher P, Asfar P. Does vasopressor therapy have an indication in hemorrhagic shock? Ann Intensive Care. 2013; 3:13-6.

23. Bulger EM, May S, Kerby JD, Emerson S, Stiell IG, Schreiber MA, Brasel KJ, Tisherman SA, Coimbra R, Rizoli S, et al. ROC investigators. Out-of-hospital hypertonic resuscitation after traumatic hypovolemic shock: a randomized, placebo controlled trial. Ann Surg. 2011:253:431-41.

24. Collier B, Dossett L, Mann M, Cotton B, Guillamondegui O, Diaz J, Fleming S, May A, Morris J. Vasopressin use is associated with death in acute trauma patients with shock. J Crit Care. 2010;25:173 e9-14.

25. Gauss T, Hamada S, Duchateau F, Eurin M, Mantz J, Paugam-Burtz C eds. Prehospital use of norepinephrine does not reduce total amount of 
prehospital fluid in hemorrhagic shock. Intens Care Med. New York: Springer; 2011:S151.

26. Hamada SR, Gauss T, Pann J, Dünser M, Leone M, Duranteau J. European trauma guideline compliance assessment: the ETRAUSS study. Crit Care. 2015;19:1.

27. Maegele M, Lefering R, Yucel N, Tjardes T, Rixen D, Paffrath T, Simanski C, Neugebauer E, Bouillon B, AG Polytrauma of the German trauma society (DGU). Early coagulopathy in multiple injury: an analysis from the German trauma registry on 8724 patients. Injury. 2007;38(3):298-304.

28. Sterm SA. Low-volume fluid resuscitation for presumed hemorrhagic shock: helpful or harmful? Curr Opin Crit Care. 2001;7:422-30.

29. Pieper A, Thony F, Brun J, Rodière M, Boussat B, Arvieux C, Tonetti J, Payen $J \mathrm{~J}$, Bouzat P. Resuscitative endovascular balloon occlusion of the aorta for pelvic blunt trauma and life-threatening hemorrhage: a 20-year experience in a level I trauma center. J Trauma Acute Care Surg. 2018:84(3):449-53.

30. DuBose JJ, Scalea TM, Brenner M, Skiada D, Inaba K, Cannon J, Moore L, Holcomb J, Turay D, Arbabi CN, et al. The AAST prospective aortic occlusion for resuscitation in trauma and acute care surgery (AORTA) registry: data on contemporary utilization and outcomes of aortic occlusion and resuscitative balloon occlusion of the aorta (REBOA). J Trauma Acute Care Surg. 2016; 81(3):409-19.

31. Brenner M, Teeter W, Hoehn M, Pasley J, Hu P, Yang S, Romagnoli A, Diaz J, Stein D, Scalea T. Use of resuscitative endovascular balloon occlusion of the aorta for proximal aortic control in patients with severe hemorrhage and arrest. JAMA Surg. 2018;153(2):130-5.

32. Norii T, Crandall C, Terasaka Y. Survival of severe blunt trauma patients treated with resuscitative endovascular balloon occlusion of the aorta compared with propensity score-adjusted untreated patients. J Trauma Acute Care Surg. 2015;78(4):721-8.

33. Joseph B, Zeeshan M, Sakran JV, Hamidi M, Kulvatunyou N, Khan M, O'Keeffe T, Rhee P. Nationwide analysis of resuscitative endovascular balloon occlusion of the aorta in civilian trauma. JAMA Surg. 2019. https:// doi.org/10.1001/jamasurg.2019.0096 [Epub ahead of print].

\section{Publisher's Note}

Springer Nature remains neutral with regard to jurisdictional claims in published maps and institutional affiliations.

Ready to submit your research? Choose BMC and benefit from:

- fast, convenient online submission

- thorough peer review by experienced researchers in your field

- rapid publication on acceptance

- support for research data, including large and complex data types

- gold Open Access which fosters wider collaboration and increased citations

- maximum visibility for your research: over $100 \mathrm{M}$ website views per year

At $\mathrm{BMC}$, research is always in progress.

Learn more biomedcentral.com/submissions 